ИЗВЕСТИЯ АКАДЕМИИ НАУК ЭСТОНСКОП ССР. ТОМ 24 ХИМИЯ - ГЕОЛОГИя. 1975, N1 1

Ю. ЛИЛЛЕ, Сильвия РАНГ, Лууле БНТТЕР

\title{
МАСС-СПЕКТРЫ МЕТИЛОВЫХ ЭФИРОВ АЛКИЛРЕЗОРЦИНОВ
}

Общие пути распада алкилариловых эфиров под действием электронного удара известны. Так, метиловые $(\mathrm{Me})$ эфиры оксибензола и его метилпроизводных, а также диоксибензолов расщепляются с выделением фрагментов $\mathrm{CH}_{2} \mathrm{O}, \mathrm{CHO}, \mathrm{CO}, \mathrm{CH}_{3}$ и $\mathrm{H}^{\left[{ }^{1-3}\right]}$. Алкильные цепи в ароматических соединениях отщепляются в В-положении по отношению к яд. py [']. Однако в литературе мало конкретных примеров спектров Меэфиров алкилфенолов [ $\left.{ }^{4}\right]$, в частности алкилрезорцинов [5]. В ходе систематического исследования методов синтеза и свойств алкилрезорцинов были получены масс-спектры ряда Ме-эфиров, которые приводятся ниже.

Рассмотрим спектры Ме-эфиров 2-метил-, 2-н-пропил-, 2-н-бутил-, 2-нгексил-, 2-н-нонил-, 5-метил-, 5-н-гептил-, 5-н-децил-, 5-метил-2-н-гексил-, 5 -метил-2-н-нонил- и 2-н-гексил-5-н-гептилрезорцина (в табл. 1,2 и 3 приведены лики, интенсивность которых выше $1 \%$ от интенсивности максимального пика).

В спектре I были обнаружены метастаб́льные ионы с массами 68,4 , $80,9,83,6,96,3$ и 99,6 (обозначены соответственно от $m_{1}^{*}$ до $m^{*}{ }_{5}$ ), что позволяет изобразить расщепление указанных соединений по следующей схеме, объясняющей образование интенсивных пиков с $m_{/} / e 137,123,121$,

Приведенная схема несколько упрощена, поскольку в спектре имеются также ионы с $m / e$ M-1 и двухзарядные ионы. Последние обнаруживаются по ионам с $m / e 75,75,5,76$ и 76,5 с интенсивностями соответственно $10,1,22$ и $15 \%$.

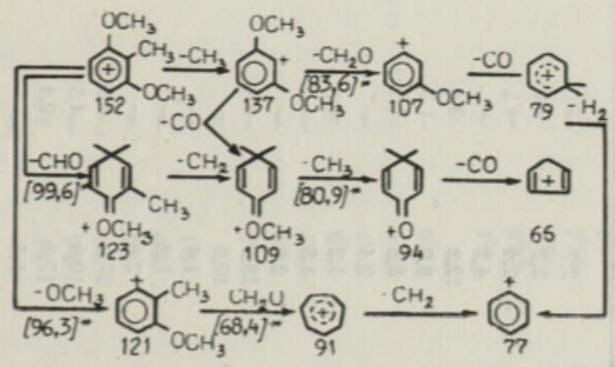

Қартина распада VI несколько проще по сравнению с распадом I. Доминирует выделение СНО-единицы с образованием интенсивного пика с $m / e 123$ (об этом свидетельствует метастабильный ион с $m / e 99,6$ ). 


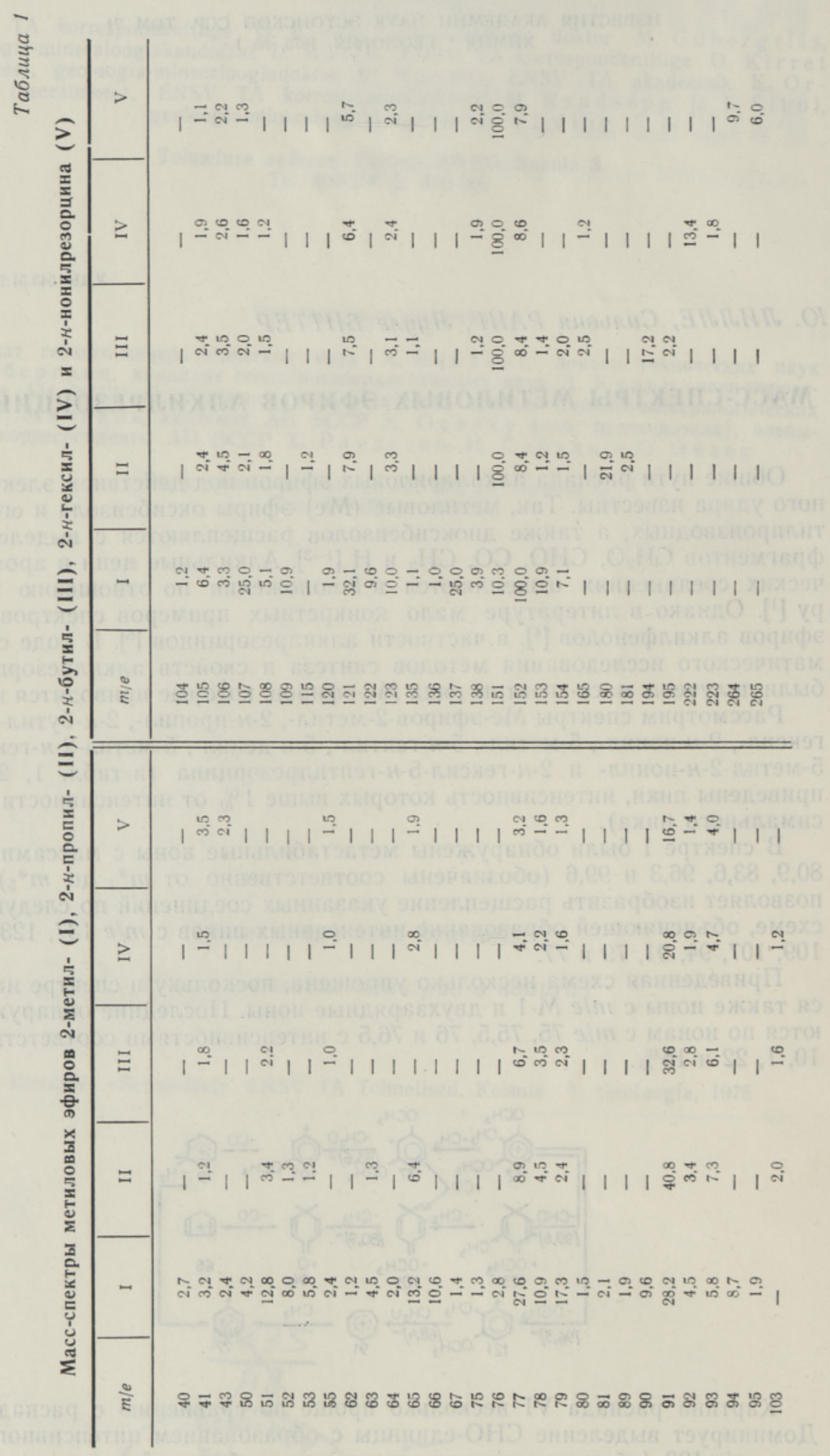




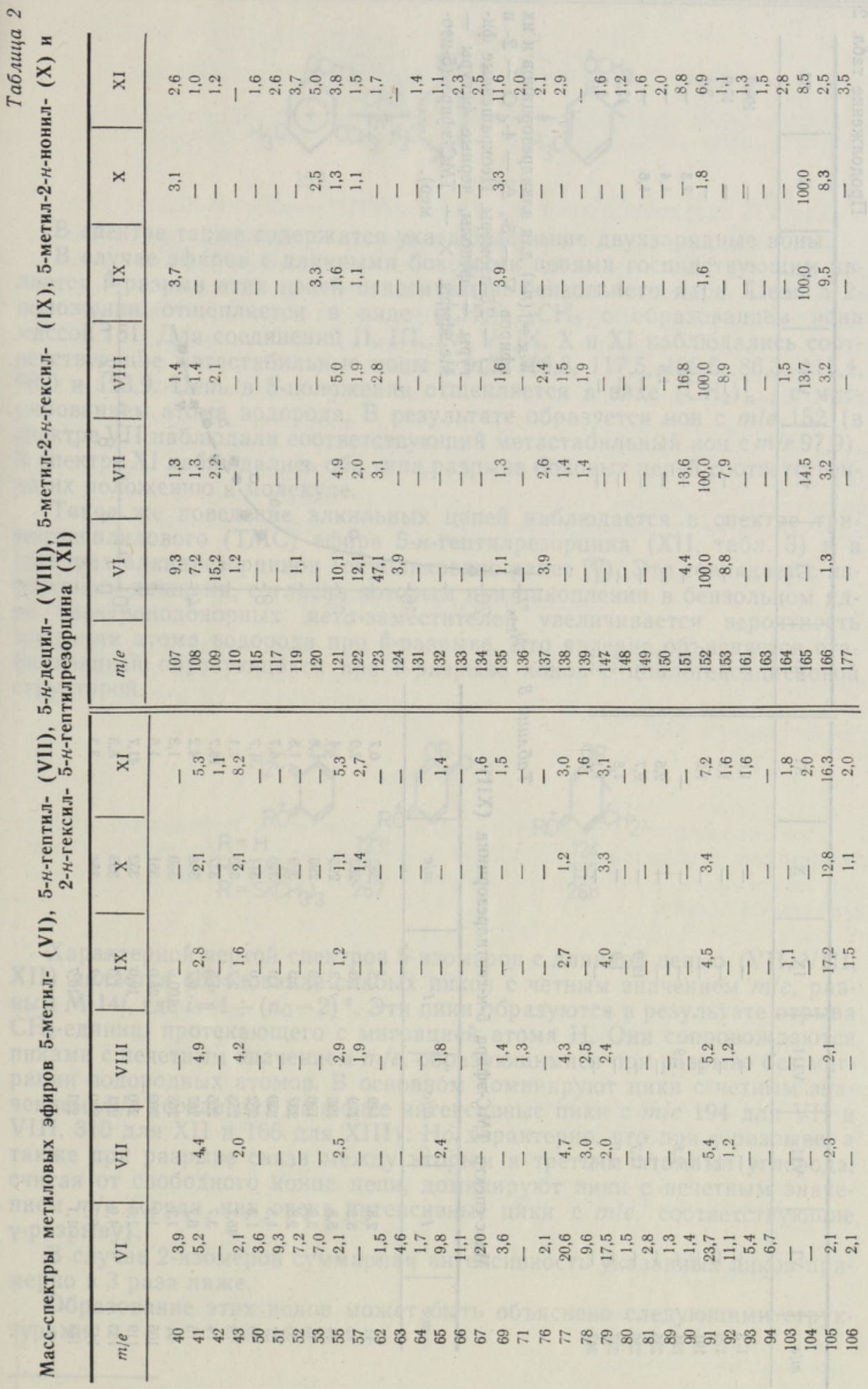




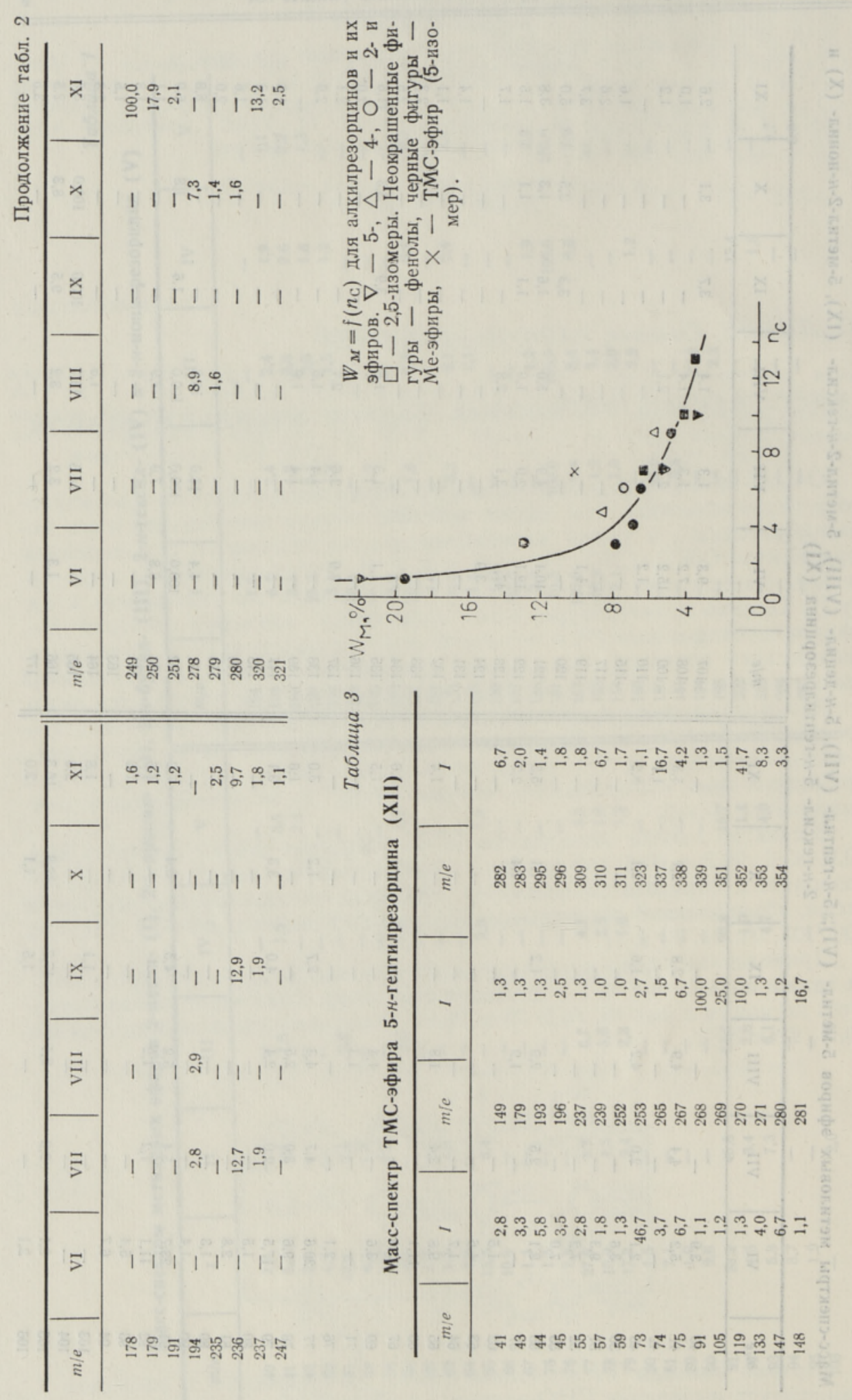




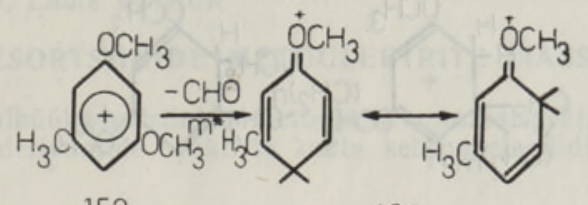

152

123

В спектре также содержатся указанные выше двухзарядные ионы.

В случае эфиров с длинными боковыми цепями господствующим является $\dot{\beta}$-разрыв этих цепей относительно бензольного ядра. Цепь в 2 положении отщепляется в виде $\left(\mathrm{CH}_{2}\right)_{n-2} \mathrm{CH}_{3}$ с образованием иона массой 151. Для соединений II, III, IV, V, IX, X и XI наблюдались соответствующие метастабильные ионы с $m / e$ 126,8, 117,5, 102,6, 86,3, 115,4, 98,0 и 193,9 . Цепь в 5 -положении отщепляется в виде $\left(\mathrm{CH}_{2}\right)_{n-1}$ с мигрированием атома водорода. В результате образуется ион с $\mathrm{m} / \mathrm{e} 152$ (в спектре VII наблюдали соответствующий метастабильный ион с $m / e$ 97,9). В спектре XI наблюдались оба типа разрыва боковых цепей соответственно их положению в молекуле.

Такое же поведение алкильных цепей наблюдается в спектре триметилсилилового (ТМC) эфира 5-н-гептилрезорцина (XII, табл. 3) и в спектрах алкилрезорцинов (опубликовано ранее [6]). Это совпадает с известными данными, согласно которым при накоплении в бензольном ядре электронодонорных мета-заместителей увеличивается вероятность миграции атома водорода при $\beta$-разрыве. Это явление объясняется стабилизацией образующихся при $\beta$-разрыве ионов с циклогексадиеновой структурой.


Характерной чертой спектров 5-изомеров с длинной цепью (VII, VIII, XII) является образование слабых пиков с четным значением $m / e$, равным $M-14 i$, где $i=1 \div\left(n_{\mathrm{C}}-2\right) *$. Эти пики образуются в результате отрыва $\mathrm{CH}_{2}$-единиц, протекающего с миграцией атома Н. Они сопровождаются пиками с нечетным значением $m / e$, образующимися при разрыве без миграции водородных атомов. В основном доминируют пики с четным значением $m / e$ (среди них наиболее интенсивные пики с $m / e 194$ для VII и VIII, 310 для XII и 166 для XIII). Но характерно, что при $\gamma$-разрыве, а также при разрыве связи между вторым и третьим атомами углерода, считая от свободного конца цепи, доминируют пики с нечетным значением $m / e$ (среди них очень интенсивные пики с $m / e$, соответствующие $\gamma$-разрыву).

В случае 2-изомеров суммарная интенсивность указанных пиков примерно в 3 раза ниже.

Образование этих ионов может быть объяснено следующими структурами:

* $n_{\mathrm{C}}-$ чнсло атомов углерода в боковой цепи. 


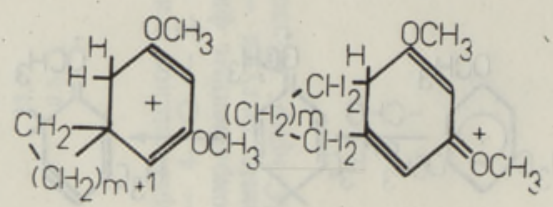

Для VII предпочтительно $m=2$, а для VIII $m=3$ и $m=6$.

TMC-эфирам характерны более «чистые» спектры по сравнению с Ме-эфирами. Возможно, что это обусловлено выделением больших $\mathrm{Si}\left(\mathrm{CH}_{3}\right)_{3}$ фрагментов (характерный ион с $\mathrm{m} / \mathrm{e} 73$, интенсивность пика которого составляет $45 \%$ от интенсивности пика с $m / e 268$, соответствующей $\beta$-разрыву), сопровождаемым значительным понижением энергии молекулярного иона. Характерный пик с $m / e$ M-15, по всей вероятности, обусловлен отрывом $\mathrm{CH}_{3}$-единицы от той же функциональной группы [7].

Стабильность молекулярного иона $W_{M}$, определяемая как интенсивность пика молекулярного иона по отношению к полному ионному току, в пределах $n_{\mathrm{C}}=1 \div 13$ зависит только от длины цепи и резко падает при увеличении последней (рис. 1). Отсутствие зависимости от положения цепи объясняется резонансными структурами, приведенными выше.

\section{Экспериментальная часть}

Синтез изученных эфиров описан в [8]. Спектры регистрировались на приборе МХ-1301 при энергии ионизирующих электронов 50 эв, токе эмиссии катода 1,5 ма, ускоряющем напряжении 2,2 кв и температуре узлов прибора $200^{\circ} \mathrm{C}$.

\section{Заключение}

Описаны масс-спектры ряда эфиров (в основном метиловых) алкилрезорцинов и показано, что общие закономерности в изученных спектрах согласуются с известными корреляциями, установленными для производных бензола.

\section{ЛИ Т ЕР А Т У РА}

1. Будз и кевич Г., Д жер асси К., У илья м с Д., Интерпретация масс-спектров органических соединений, М., 1966, с. 198.

2 B arnes C. S., Occolowitz I. L., Austr. J. Chem., 16, 219 (1963).

3. Pelah Z., Wilson I. M., Ohashi M., Budzikiewicz H., Djerassi C., Tetrahedron, 19, 2233 (1963).

4. Atlas of Mass Spectral Data, 1-3., Interscience Publishers, 1969.

5. Occolowitz I. L., Anal. Chem., 36, 2177 (1964).

6. Бродский Е. С., Лилле Ю. Э., Лукашенко И. М., Биттер Л. А., Поля к о в а А. А., ЖОрХ, 6, 2096 (1970).

7. Smith G. G., D jerassi K., Org. Mass. Spectrom., 5, 487 (1971).

8. Лилле Ю. Э., Биттер Л. А., Кундель Х. А., Тр. НИИ сланцев, вып. 19, Таллин, 1973.

\section{НИИС Институт сланцев}

Институт химии

Академии наук Әстонской ССР
Поступила в редакцию 26/VI 1973 
J. LILLE, Silvia RANG, Luule BITTER

\section{ALKUOLRESORTSIINIDE METUULEETRITE MASSISPEKTRID}

Kirjeldatakse rea alküülresortsiinide metüüleetrite massispektreid ja sedastatakse, et need alluvad bensooli derivaatide spektrite kohta kehtivatele üldistele seaduspärasustele.

\section{J. LILLE, Silvia RANG, Luule BITTER}

\section{MASS SPECTRA OF ALKYL RESORCINOL METHYL ETHERS}

A number of mass spectra of alkyl resorcinol methyl ethers are described. It is shown that the general features of the spectra correspond to the common rules valid for benzene derivatives. 